\title{
A PERFORMANCE DO MITO? EMPRESARIADO DO "FRACASSO" E A DINÂMICA REGIONAL DO PODER
}

\author{
Marcus Vinicius Spolle ${ }^{1}$ \\ Elaine da Silveira Leite ${ }^{2}$ \\ Vanesca Pires Trindade Cantarelli ${ }^{3}$
}

\begin{abstract}
Resumo: Esse artigo visa desvelar as percepções que envolvem a performance da teoria do contraste metade-norte e metade-sul como a "principal" teoria histórica e explicativa do atual desenvolvimento econômico do Estado Rio Grande do Sul. Essa teoria sustenta a tese que distingue a metade-sul como atrasada pois, historicamente, foi marcada pela grande propriedade, pelo latifúndio, e por um conservadorismo que inibiu o desenvolvimento de um "espírito empreendedor", o qual figura como forte característica da "metade-norte", que registra um passado marcado pela pequena propriedade, pela economia agrícola, e demais atividades econômicas que envolvem setores mais diversificados, etc. Essa teoria, portanto, revela as características do passado de colonização do início do século XX e, que sem dúvida, ainda reflete na realidade sócio-política da região. Entretanto, buscamos problematizar como essa proposição tornou-se recorrente nas explicações do senso comum do gaúcho. Para isso, adentramos no mundo das famílias locais que mantém negócios próprios (médios e pequenos empresários) e estão em evidência, nos últimos anos, com estandes na principal feira de exposição da cidade de Pelotas (município da metade sul do Rio Grande do Sul) - a FENADOCE (Feira Nacional do Doce).
\end{abstract}

Palavras-chave: Família políticas. Pelotas/RS. FENADOCE.

\section{THE PERFORMANCE OF THE MYTH? COMPANY OF "FAILURE" AND THE REGIONAL DYNAMICS OF POWER}

\begin{abstract}
This paper aims to reveal the perceptions that involve the performance of the half-north and half-south contrast theory as the "main" historical and explanatory theory of the current economic development of the State of Rio Grande do Sul. This theory supports the thesis that distinguishes The south-half as backward, since it has historically been marked by large estates, by latifundia, and by a conservatism that inhibited the development of an "entrepreneurial spirit," which is a strong characteristic of the "north-half". Past by small property, agricultural economy, and other economic activities involving more diversified sectors, etc. This theory, therefore, reveals the characteristics of the colonization past of the early twentieth century and, undoubtedly, still reflects on the socio-political reality of the region. However, we try to problematize how this proposition became recurrent in the explanations of the gaucho's common sense. In order to do this, we enter the world of local families that have their own businesses (middle and small business) and have been in evidence in recent years with booths at the main exhibition fair of the city of Pelotas (municipality of the southern half of Rio Grande do Sul) - FENADOCE (National Fair of the Doce).
\end{abstract}

Keywords: Family policies. Pelotas / RS. FENADOCE

- Enviado em 15/07/2017

- Aprovado em 28/07/2017

${ }^{1}$ Doutor em Sociologia pela Universidade Federal do Rio Grande do Sul e Professor de Sociologia da Universidade Federal de Pelotas.

${ }^{2}$ Doutora em Sociologia pela Universidade Federal de São Carlos e Professora de Sociologia da Universidade Federal de Pelotas (UFPel) e do Programa de Pós-graduação em Sociologia (UFPel), coordenadora do GENS (Grupo de Estudos em Novas Sociologias - Econômica, Finanças e Família). E-mail: elaineleite10@ gmail.com.

${ }^{3}$ Graduanda do curso de bacharelado em Ciências Sociais da Universidade Federal de Pelotas.

Uma versão preliminar desse texto foi apresentada no $18^{\circ}$ Congresso Brasileiro de Sociologia. Que Sociologia azemos? Interfaces com contextos locais, nacionais e globais realizado de 26 a 29 de julho de 2017 no Centro de Convenções Ulysses Guimarães, Brasília/DF. 


\section{Introdução $^{4}$}

Essa comunicação visa desvelar as percepções que envolvem a performance da teoria do contraste metade-norte e metade-sul como a "principal" teoria histórica e explicativa do atual desenvolvimento econômico do Estado Rio Grande do Sul. Essa teoria sustenta a tese que distingue a metade-sul como atrasada pois, historicamente, foi marcada pela grande propriedade, pelo latifúndio, e por um conservadorismo que inibiu o desenvolvimento de um "espírito empreendedor", o qual figura como forte característica da "metade-norte", que registra um passado marcado pela pequena propriedade, pela economia agrícola, e demais atividades econômicas que envolvem setores mais diversificados, etc.

Essa teoria, portanto, revela as características do passado de colonização do início do século XX e, que sem dúvida, ainda reflete na realidade sócio-política da região. Entretanto, buscamos problematizar como essa proposição tornou-se recorrente nas explicações do senso comum do gaúcho. Para isso, adentramos no mundo das famílias locais que mantém negócios próprios (médios e pequenos empresários) e estão em evidência, nos últimos anos, com estandes na principal feira de exposição da cidade de Pelotas (município da metade sul do Rio Grande do Sul) - a FENADOCE (Feira Nacional do Doce).

Até o momento, foram entrevistados nove empresários(as) do município de Pelotas que já participaram da FENADOCE. Todos os empresários entrevistados, nesta etapa da pesquisa, já empreenderam nos mais diferenciados ramos do comércio varejista, tais como, agroindústria, confeitaria, doces, confecções, restaurante, próteses dentárias, viagens e turismo. A partir desta investigação exploratória, notamos a recorrência de um discurso do "atraso" e do "fracasso" que marca os depoimentos dos entrevistados; isto é, a performance do mito relacionada ao "princípio explicativo regional” (LEITE; SPOLLE, 2014) como entrave do desenvolvimento econômico, que subjetivamente "se fecha" para o "novo" espírito empreendedor; e que, no entanto, sustenta as (antigas) formas de organizações (políticas e econômicas) de poder concentradas nas tradicionais

\footnotetext{
${ }^{4}$ Uma versão preliminar deste artigo foi apresentado em: LEITE, E. S.; SPOLLE, M. V. Desvelando as contradições da teoria do desenvolvimento do Rio Grande do Sul. In: V Seminário Nacional de Sociologia e Política: desenvolvimento e mudanças sociais em contexto de crise, 2014, Curitiba - PR. Anais: V Seminário Nacional de Sociologia e Política, 2014.

${ }^{5}$ Para este artigo, usaremos a expressão empresário como sinônimo de empreendedor, pois de acordo com Leite e Mello (2008), hoje, temos a naturalização do termo empreendedor como empresário. Para maiores detalhes: LEITE, E. S.; MELO, N. M. E. Uma nova noção de empresário: a naturalização do 'empreendedor'. REVISTA DE SOCIOLOGIA E POLÍTICA (UFPR. IMPRESSO), v. 31, p. 35, 2008.
} 
famílias pelotenses, a qual venera o passado glorioso do auge econômico da época da dinâmica do charque de 1780 até, aproximadamente, 1865, quando ocorre a decadência da economia subsidiária devido a evasão de escravos para as lavouras de Café Paulista, e a concorrência do charque dos saladeiros uruguaios.(Cardoso, 2003).

Isto posto, este artigo apresenta as primeiras evidências do projeto de pesquisa, intitulado: "Desvelando as contradições da teoria do desenvolvimento econômico do Rio Grande do Sul", desenvolvido no âmbito do Programa de Pós-graduação em Sociologia da Universidade Federal de Pelotas, que visa esboçar a performance do mito que compõe o imaginário social da região seja via a legitimação intelectual advinda do campo acadêmico, bem como através do reportório cultural dos empresário locais. Assim, consideramos como mito, a teoria do contraste metade-norte e metade-sul como a principal teoria que explica o atual desenvolvimento econômico do Rio Grande do Sul e é legitimada socialmente pelos referidos agentes, problematizando, portanto, como essa teoria ganhou dimensões que extrapolam o ambiente acadêmico e tornaram-se explicações recorrentes do senso comum do gaúcho. Deste modo, pretende-se relacionar o impacto de tal teoria, em especial, advinda do campo acadêmico, com a formação de um "mito" econômico do contraste entre as metades do Rio Grande do Sul, que hoje parecem (subjetivamente) atuar como alimentadora de repertórios culturais que podem (na prática) atravancar o desenvolvimento econômico de uma região. Mais precisamente, desejamos buscar novas possibilidades heurísticas para refletir sobre o desenvolvimento econômico gaúcho e as novas formas de organizações e poder emergidas no atual cenário político-econômico da região, não contaminadas pelo conhecimento científico tradicional.

Deste modo, para este artigo apresentaremos como o mito é sustentado pelo repertório orquestrado dos empresários locais. Aqui, além do "princípio explicativo regional” soma-se o "peso" em justificar o inibido dinamismo econômico atual pelo passado glorioso da época do charque, bem como do recente declínio do Polo Naval e a expectativa de que no futuro a região sairá da maldição do fracasso.

Assim, este artigo está divido em duas partes; a princípio, apresentaremos a história econômica da região de Pelotas, do ponto de vista ordinário, isto é, de como a história do passado "glorioso" da época do charque é evocada até adentramos na tradicional festa do doce (FENADOCE) para abordar a orquestração do repertório dos empresários sobre a dinâmica local. 


\section{"Do sal ao açúcar"; e a performance do "fracasso"7}

O Estado do Rio Grande do Sul (RS) é marcado historicamente pela diferença na forma de ocupação territorial entre o meio-norte e o meio-sul, tal demarcador é uma das principais justificativas empregada pela maioria dos acadêmicos, que buscam explicar as possíveis características entre as esferas da economia, da política e do social que caracterizam as regionalidades do referido estado (LEITE; SPOLLE, 2014).

Deste modo, a região sul do estado é conhecida pelo latifúndio, pela pecuária e atividades agrícolas ligadas à monocultura, e vem perdendo sua importância econômica, ao longo século XX. Já a região norte, além do seu perfil agropecuário produtivo, caracterizado pela diversidade econômica e pela pequena propriedade também apresenta significativos avanços nos setores industriais, em especial a região localizada a oeste da metade-norte - caracterizando as atividades do nordeste do estado ${ }^{8}$. Dentro dessa perspectiva, uma das principais correntes teóricas sobre o desenvolvimento do Rio Grande do Sul destaca a existência de uma matriz produtiva diversificada; entretanto, ela é marcada pela assimetria regional.

A produção industrial gaúcha, de acordo com Reichel (1979), durante a República Velha, era a terceira força industrial do país, entretanto, apresentava características específicas de organização industrial, diferenciando-se da região sudeste, considerada referência do setor industrial no país. A organização industrial, portanto, era composta por pequenas empresas que operavam com reduzido volume de capital investido na produção e baixo nível tecnológico, isto é, a cultura industrial possuía uma estrutura quase que artesanal. Entretanto, cabe ressaltar, segundo a autora, que o setor têxtil se distinguia desse perfil, pois atendia outros padrões de produção e, neste caso, se assemelhava aos modelos industriais das regiões mais industrializadas na época do país (REICHEL, 1979). Apesar, da industrialização seguir rumos peculiares, o Rio Grande do Sul apresentava altos

\footnotetext{
${ }^{6}$ A referência "do sal ao açúcar" é uma ideia recorrente que sintetiza os ciclos econômicos vivenciados na cidade de Pelotas, por exemplo, ver: http://www.docesdepelotas.org.br/foopage/. Acesso: 12 de junho de 2017.

${ }^{7}$ Vale ressaltar ao leitor que quando chamamos a atenção para o "fracasso", o intuito não é estigmatizar, bem como não temos a intenção de valorar as atitudes. O nosso objetivo é compreender como se constitui o repertório dos empresários locais sobre a dinâmica econômica atual, a qual até o momento, as evidências corroboram a hipótese da performance do mito do "princípio explicativo regional" (LEITE; SPOLLE, 2014).

${ }^{8}$ Alguns acadêmicos dividem o território do Rio Grande do Sul em 3 regiões, de acordo com suas características socioeconômicas. A metade-sul caracterizada pela agropecuária e lavoura extensiva - agrega menor valor à produção. A metade-norte tem sua atividade concentrada no setor primário dinamizado, pois concentra atividades com bases modernas e incorporadoras de insumo industriais. E, a região nordeste, onde se concentra o maior percentual do PIB do estado, marcada pela forte presença do setor industrial (HEINDRICH, 2000, p. 126). Apesar dessa diferenciação em três regiões, neste trabalho, seguimos abordando o desenvolvimento do RS pelo eixo metade-norte (dinâmico e diverso) e metade-sul (atrasado).
} 
índices de lucratividade; portanto, tal desempenho é visto como decorrência da "industrialização de caráter regional”.

Deste modo, o desenvolvimento, tanto do setor agrícola como do setor industrial, é reforçado pela ideia do "caráter regional", que passa a estruturar os caminhos do desenvolvimento econômico e marcam as características das metades do Rio Grande do Sul, que levam em conta a forma de ocupação territorial, bem como, a cultura advinda dos imigrantes.

O papel do Rio Grande do Sul no desenvolvimento da economia nacional também é outro fator marcante que alimenta, de modo geral, o que intitulamos de "princípio explicativo regional" (LEITE; SPOLLE, 2014). Isto posto, as explicações sobre o "não desenvolvimento" e o "não crescimento econômico" da indústria do Rio Grande do Sul, por exemplo, decorre da ênfase na localização, que por se tratar de uma região de fronteira, o estado teve maiores envolvimentos com “guerras" para a conservação e conquista do território (REICHEL, 1979), portanto, levando a “acentuação" do caráter regional da industrialização gaúcha, já que o escoamento da produção foi direcionado para o sustento interno do país e da região. Para a refira autora, naquele momento, os industriais entusiasmados com o aumento do consumo de ordem regional e limitados pelo escoamento da produção não perceberam que tal crescimento era "circunstancial" e que no âmbito nacional, o Rio Grande do Sul perdia espaço no que tange aos benefícios advindos do processo de exportação.

Antes de mais nada, vale enfatizar que a economia da região sul do Estado, até o início do século XX, é entendida como subsidiária e escravista, o seu principal produto era o charque que vinha da intensa atividade pecuária, constituída econômica, política e socialmente nos moldes de uma estrutura patrimonialista.

$\mathrm{Na}$ verdade, a sociedade Rio-grandense não só se organizou nos moldes de uma estrutura patrimonialista, como às posições assimétricas na estrutura social correspondiam formas de comportamento reguladas por rígidas expectativas de dominação e subordinação. Frequentemente a compatibilidade entre as expectativas era assegurada pelo exercício violento e arbitrário da autoridade inerente às posições hierarquicamente superior do sistema social (CARDOSO, 2003, p. 108).

De acordo com Cardoso (2003), cabe destacar que a compreensão do processo de desenvolvimento da economia sulina depende da análise da função econômica que ela desempenhou, graças à maneira peculiar pela qual se articulou com o que se poderia designar com a economia propriamente colonial do Brasil, isto é, como o setor exportador da economia. Isto posto, 
a economia da metade-sul articulou-se via uma economia subsidiária, mas de vital importância para seu desenvolvimento (CARDOSO, 2003, p. 57).

Até a segunda metade do século XIX, a região sul era a protagonista econômica do estado pois contava com a produção latifundiária voltada para a pecuária, em especial, o setor charqueador e a lavoura de arroz; assim, neste momento, passa a perder espaço para as atividades de lavouras mecanizadas, em especial, de soja e de trigo das pequenas e médias propriedades da região norte, bem como, a intensificação de setores industriais da região norte (ALONSO, et al 1994).

De modo geral, o "princípio explicativo regional” (LEITE, SPOLLE; 2014) está diretamente associado a fatores geográficos que influenciaram o desenvolvimento das atividades produtivas e, por consequência, o desempenho econômico das regiões. Assim, as explicações das diferenças entre as metades consideram que a metade-sul formada por grandes extensões de terra é mais adaptável à criação de gado, a atividade da pecuária, e a região norte, considerando a irregularidade de seu relevo, foi estimulada à formação de pequenas propriedades e incitada pela agricultura diversificada.

Entre questões de ocupação do territorial e imigração surgem as principais justificativas sobre as discrepâncias que marcam o estado do Rio Grande do Sul. Diante deste cenário, o "princípio explicativo regional" ganha legitimidade, em especial, pelas teorias acadêmicas (LEITE; SPOLLE, 2014) e serve de justificação no senso comum para o desenrolar de atividades econômicas na região, limitando, em especial, a metade-sul a seu caráter de atraso e destinando os empresários ao "fracasso".

Historicamente, a metade-sul enfrentou dificuldades econômicas em decorrência do declínio do setor agropecuário e do reduzido (ou quase inexistente) processo de industrialização. Essa metade, hoje, encontra-se em estagnação desde as crises na agricultura da década de 1980, e mesmo com os recentes investimentos na região advindo do governo federal, com a criação do Polo Naval de Rio Grande (cidade localizada a cinquenta quilômetros da cidade de Pelotas) que trouxe por alguns por anos (2006-2014) "ares" de esperança e de retomada da dinâmica econômica, mas devido a atual crise econômica e política, a "maldição" da estagnação assombra novamente o imaginário social.

Assim, Rio Grande e Pelotas, que foram polos de desenvolvimento (em alguns momentos específicos), persistem em decadência econômica. Enquanto, a metade-norte passa a configurar

\footnotetext{
${ }^{9}$ A ideia de que a região é amaldiçoada advém da construção, digamos de outro "mito" local da "maldição" de SaintHilaire, quando o viajante ao constatar a situação adversa do vento e areia, afirma: "O progresso dessa cidade é devido unicamente ao fato de ali estar situada a alfândega(...). Priva-se dessa proteção oficial, inteiramente contrária a ordem natural das coisas, e ela entrará em decadência" (Saint- Hilaire,2002,106).
} 
novamente como a região economicamente mais desenvolvida do Estado. E, entre "mitos" e “maldições" o "princípio explicativo regional” parece performar a realidade local.

Neste sentido, é que constatamos e passamos a evidenciar nas falas dos empresários locais a referência constante e nostálgica de que Pelotas já foi uma cidade rica, assim, o imaginário social está simbolicamente atrelado ao passado, o qual as cidades (Pelotas e Rio Grande) viveram seu ápice econômico com a salga da carne, via a produção do charque, como enfatiza a fala abaixo.

Acho que muitas coisas nós somos empreendedores mesmo, no início quando os bandeirantes vieram para cá, foi empreendedorismo mesmo, no tempo do charque mesmo, as barcas saiam daqui cheias de arroz para o nordeste, naquela época nós éramos muito empreendedores, hoje eu acho que estamos muito mal. (...) Ah sim, estagnou mesmo, tanto é que no tempo da Charqueada, nós éramos uma metrópole, os filhos das pessoas com mais condições iam para a França para estudar, era muito comum, depois o Norte começou a crescer, a Serra mesmo é hoje um polo metalúrgico e Pelotas e Rio Grande parou. (Entrevistado A)

Assim, com o surgimento dos frigoríficos, a economia do charque entra em decadência, e naquele momento, Pelotas encontra a sua vocação de cidade do doce - "Os doces foram introduzidos pelos lusos por volta do início do século XIX e em Pelotas aproximadamente na década de 1860, quando começa o período de apogeu do município de Pelotas"10. Em 1920, Pelotas passa a ser reconhecida pela "tradição doceira que até então estava restrita ao interior dos casarões" 11 das charqueadas, seguido também para o cultivo de frutas, como o pêssego, iniciando-se a fabricação dos doces de compota, das geleias e da conserva ${ }^{12}$.

A indústria do doce é, atualmente, considerada uma das principais atividades econômicas locais, além da indústria do arroz. Neste interim, vale destacar que ao buscarmos a história econômica da cidade de Pelotas e a referência como capital do doce; encontramos no sítio da Associação dos Produtores de Doces em Pelotas (APDPEL), a seguinte referência: "Na história econômica do município destaca-se a produção do charque que era enviado para todo o Brasil, e fez a riqueza de Pelotas em tempos passados"13. Aqui, é interessante notar que a própria associação dos produtores que dá a titulação (de capital nacional do doce) ao município enfatiza muito a euforia econômica do passado, o que é reforçado pelo seguinte trecho: "os processos que envolveram o açúcar e o sal foram complementares para o progresso econômico e cultural de Pelotas. Embora a

\footnotetext{
${ }^{10}$ Informações retirada do sítio da Associação dos Produtores de Doces em Pelotas (APDPEL). Disponível em: http://www.docesdepelotas.org.br/foopage/. Acesso 12 de junho de 2017.

${ }^{11}$ Idem.

12 Idem.

${ }^{13}$ Idem.
} 
indústria local de doces e conservas ainda não tenha recuperado o desenvolvimento registrado no município entre 1860 a 1890, esta é uma tradição a qual faz parte da formação da identidade histórica da cidade (...)"14.

Assim, vale destacar que o peso simbólico da época das charqueadas está no próprio nome do município "Pelotas", no qual sua origem vem das embarcações que eram feitas de couro (pelota) e usadas para o transporte do charque pelos arroios que cortavam as charqueadas.

Hoje, portanto, a FENADOCE, é a principal feira de negócios da cidade e da região de Pelotas. A feira em 2017, está na vigésima quinta edição do evento e tem como objetivo promover os doces e seus fabricantes, bem como agrega demais empresários para a exposição dos negócios locais ${ }^{15}$, de acordo com o sítio do evento:

A Fenadoce nasceu em 1986, criada pelo Poder Público juntamente a outras entidades. A Câmara de Dirigentes Lojistas de Pelotas - CDL — assumiu a coordenação do evento em 1995. Nas primeiras edições, acontecia a cada dois anos, sempre em um local diferente da cidade. A partir de 1988, a Feira tornou-se anual e ganhou endereço fixo: o Centro de Eventos Fenadoce (...). Hoje, a Fenadoce atrai visitantes de fora, tanto do país quanto do Mercosul. Convidados ilustres da área da política e do entretenimento sempre comparecem. Para as doceiras, é a oportunidade de vender e divulgar os deliciosos doces pelotenses. Para os expositores, é a chance de entrar em contato com mais de 300 mil pessoas. Para os visitantes, a Fenadoce oferece um mundo de magia com diversas atrações culturais, gastronômicas e comerciais. Os 19 dias de evento são uma excelente oportunidade para se divertir e conhecer nossos doces e nossa história ${ }^{16}$.

Deste modo, a FENADOCE por se constituir o principal elo entre os empresários regionais e buscar expor a dinâmica econômica, cultural e até mesmo política como destaca o trecho acima, foi o ponto de partida para a seleção dos empresários para esta pesquisa. Neste sentido, entramos em contato com a comissão organizadora do evento para obter a lista de empresários expositores nos últimos anos (2010-2016), e a partir deste material iniciamos o contato para a realização das entrevistas, no próximo item elencaremos a orquestração do repertório do "fracasso".

\footnotetext{
${ }^{14}$ Idem.

${ }^{15}$ Informações retiradas do sítio do evento. Disponível em: https://www.fenadoce.com.br/. Acesso em 12 de junho de 2017.
}

${ }^{16}$ Idem. 


\section{Fracasso e atraso: a orquestração ${ }^{17}$ do repertório}

As trajetórias profissionais dos empresários, que compõem o nosso universo empírico, apresentam diferentes caminhos, cinco dos nove entrevistados sempre foram comerciantes e gestores do seu negócio; (entrevistado A e B) dois eram comerciários e depois se tornaram donos de seu próprio negócio; também temos um caso de uma funcionária pública (entrevistada C) que abandonou a carreira para se tornar empresária; outro (entrevistado I) com experiência como agricultor, caminhoneiro e, por fim, comerciante. A maioria dos entrevistados já estão atuando como empresário por mais de 20 anos. Quanto a escolaridade, cinco tem curso superior completo em diferentes áreas não relacionadas com o seu negócio, um tem curso superior completo em marketing e um está cursando gestão financeira. Dois dos entrevistados tem o ensino médio completo.

Nesse sentido, os empresários, aqui elencados, pouco investiram na sua qualificação pessoal, em termos de escolaridade. A trajetória está voltada para o empreendimento, o que de certa forma, entra em sintonia com a ideia de que o empresário é resultado de um "tino" comercial, isto é, suas características são inatas, e/ou advém de uma certa herança familiar ao mundo dos negócios; assim, na prática o investimento em educação, ou o conhecimento especializado no seu campo de trabalho não é considerado ${ }^{18}$.

Assim, iniciamos a apresentação da trajetória destes empresários relatando as percepções sobre suas experiências bem-sucedidas e as principais dificuldades encontradas no comércio varejista de Pelotas; de modo geral, evidenciamos que todos apontaram mais dificuldades que êxito no empreendimento, em parte, pela crise político-econômica de 2015 , e, principalmente, o reflexo do fechamento das atividades do Polo Naval de Rio Grande, o que resultou na demissão de 3500 (três mil e quinhentos funcionários) operários, afetando diretamente o mercado consumidor na região.

É interessante enfatizar este ponto, já que as entrevistas foram realizadas no momento do ápice da crise do Polo Naval na região com o encerramento de suas atividades; entretanto, em etapas exploratórias anteriores, os relatos também eram marcados pelo repertório das dificuldades e do atraso. O evento da demissão dos trabalhadores, neste ponto, passa a ser uma justificada

\footnotetext{
${ }^{17}$ Essa ideia advém de Bourdieu (2001), referente ao conceito de orquestração (sem maestro) do habitus; entretanto, aqui adaptamos, de certa forma, o conceito para pensar como o mito passa a ser orquestrado pelo senso comum, levando a formação do imaginário social, performado pelo mito e pela prática dos empresários do fracasso em análise.

${ }^{18}$ O município de Pelotas conta com quatro instituições de ensino superior, são elas: Universidade Federal de Pelotas, Católica de Pelotas, Instituto Federal Sul-Riograndense e Anhanguera Educacional.
} 
presente, passiva e legítima, já que pairava-se no imaginário local a crença de que o Polo, investimento advindo governo federal na região, iria tirar a localidade da estagnação. Desde a queda da economia do charque, acredita-se (no futuro) em uma possível retomada da dinâmica econômica; entretanto, o fracasso marca as experiência regionais do presente, e o "sucesso" fica relegado ao passado.

É interessante notar que juntamente com a analogia ao passado "glorioso" soma-se também a ideia da dimensão geográfica, a qual a cidade está distante do centro do país, isto é, de locais onde a economia parece "funcionar" e o desenvolvimento econômico acontece, como mencionado do item acima. Aqui vale ressaltar que a região é uma zona de fronteira, portanto, marcada historicamente pelas lutas de defesa do território, mas que socialmente são vistas como terras distantes e esquecidas no cenário nacional.

Por outro lado, seguindo a orquestração do repertorio, uma reclamação declarada por um dos entrevistados (entrevistado E) é quanto a inexistência de crédito barato para as pequenas empresas, o que, segundo ele dificulta o investimento. Vinculado a esse assunto, foi também apontado como problema o controle de estoque, e o investimento em marketing, principalmente no início do empreendimento. A dificuldade referente a questão do estoque foi realçada, já que por estarem geograficamente distante do centro do país (como enfatizado anteriormente), localizados em especial em São Paulo, relatou-se que de além de encarecer o preço do produto, impõem uma estratégia de estoque mais ordenada e custosa, o que nem sempre é possível, principalmente na área de alimentos perecíveis. Nesse item, aponta (entrevistado A) que com a internet, o sedex, a rodoviária, parte do problema foi resolvido, mas a questão geográfica marca o repertório dos entrevistados.

As justificativas do repertório também enfatizam a questão do imigrante e a relação com o trabalho, isto é, aparentemente o "princípio explicativo regional" aparece associado a questão da imigração, performando o mito e legitimando os repertórios do "atraso" e do "fracasso".

Assim, quando buscamos explicitamente compreender as percepções dos empresários sobre a performance da teoria do contraste metade-norte e metade-sul, a grande maioria dos entrevistados (A, B, D, E, I) reafirmou essa teoria das diferenças, caracterizando o sul do estado como mais consumista, onde as pessoas não poupam para investir no desenvolvimento, bem como é atrasado tecnologicamente, com predominância do latifúndio, o que gera um intenso êxodo rural, e, enfraquece o “espírito empreendedor” em setores não ligados ao agronegócio. 
Por outro lado, a explicação cultural de que nesta região vieram poucos imigrantes alemães e italianos ${ }^{19}$ adentrou no repertório dos entrevistados (B e D). Justifica-se, assim, que a metade-norte, devido ao maior número de imigrantes (alemães e italianos) foi desenvolvida uma mentalidade de poupar, trabalhar, acumular e empreender, alimentando o imaginário de que por lá as "coisas funcionam", pois as pessoas dormem e levantam cedo, trabalham e não gastam, não ostentam riqueza, pois poupam e investem. Como afirma o entrevistado:

$\mathrm{Eu}$ acredito que tem bastante cultural, e também a influência da colonização , enquanto nossa região é extremamente consumista, a região sul é o perfil nosso uma característica nossa, nosso povo se tiver dinheiro ele vai consumir e até sem dinheiro ele consome igual, já lá para cima o povo tem mais a visão de segurar de poupar de investir, de transformar o dinheiro em coisas palpáveis, material, é um empreendimento, é um negócio e o nosso povo daqui se ele tiver dinheiro ele vai consumir, em beleza, em luxo, em carro ,em vaidades, isso comprovado por pesquisas, isso é uma coisa que influencia bastante, na cultura não que não haja alemães e italianos aqui, acredito que em proporção menor. É característica do alemão e do italiano dormir cedo e acordar cedo, e passar horas do dia trabalhando, já aqui na nossa região se você sair a uma, as duas as três ou cinco da manhã você encontra gente na rua, no barzinho aberto, o pessoal curte muito mais a noite do que essas outras regiões, acho que tem bastante a ver com o perfil e comportamento, educação eu acho que pesa bastante, eu sou de origem italiana e meus pais me ensinaram que se eu ganhasse 10 deveria guardar 5, e gastar só 5 é educação também, educação financeira.(Entrevistado D)

No depoimento fica evidente a importância dada a uma espécie de educação financeira e motivação ao trabalho por parte das famílias oriundas de imigrantes, no norte do estado, e a falta desta prática na região sul do Rio Grande do Sul. Assim, o repertório local é alimento pela ideia de que o sucesso da metade-norte advém do árduo trabalho dos indivíduos e não é explicado, em nenhum momento, por incentivos e investimentos do Estado, já que outra dificuldade apontada pelos entrevistados foi a falta de apoio da Prefeitura Municipal de Pelotas, o qual (Entrevistado B) criticara a falta de incentivos fiscais para o pequeno comerciante.

De todos os entrevistados somente um empresário (Entrevistada C) afirmou que existem diferenças econômicas entre as duas regiões, que tal diferença foi intensa, mas está diminuindo principalmente em termos de desenvolvimento e de montante de investimentos.

\footnotetext{
${ }^{19}$ Aqui vale enfatizar que desdobramentos desta pesquisa irão abordar a questão da economia étnica - que envolvem tanto a questão da imigração, como também irá perpassar pela questão dos negros e quilombolas nesta dinâmica regional.
} 
Por fim, foi levantada a questão sobre a estagnação econômica na metade-sul do Rio Grande do Sul. Quatro dos entrevistados (A, C, D, E, H) afirmaram que há uma estagnação econômica na região e, segundo eles, as explicações para este fenômeno estão na questão cultural, baseada no que chamamos de "mito", bem como no estigma sobre o "não trabalho", o que é justificado pela lógica ressaltada acima da questão imigratória, bem como pela incidência de um grande número de ações trabalhistas que ocorre na cidade - o que, ao mesmo tempo, que protege o trabalhador (aquele que “não quer trabalhar", não possui o espírito do trabalho "árduo" como ocorre na metade-norte); também pode sobrecarregar o empregador (com altos custos para manter a empregabilidade e os encargos advindos dos processos trabalhistas). Vale enfatizar que este título de cidade que mais tem ações trabalhistas no Estado, e que paira no senso comum, até o momento, não foi possível confirmar, pois não encontramos dados para verificar este repertório que, independente, da veracidade dos fatos, reforça o mito do fracasso e do atraso.

Eu acho que esta estagnação vem de longos períodos de má gestão, de falta de habilidade nas negociações, nesses trinta anos eu já vi várias empresas querendo vir para nossa região e tendo essas intenções abortadas por falta dessa habilidade de nossos políticos na hora de decidirem, faltou boa vontade eu acho que é o perfil de nossa população que e conhecido hoje, praticamente pelo Brasil inteiro que Pelotense não gosta de trabalhar, não sei se agora mudou essas estatísticas, mas era uma região de maiores índices de causas trabalhistas, o que era um estigma de nossa população , então são coisas ruins que querendo ou não, uma empresa está fazendo um projeto se preparando para escolher um local onde vai ser implantada, tudo isso pesa e nós teríamos tudo para ser um polo industrial pela nossa localização, pela facilidade de mandarmos para fora tudo que nós produzimos aqui pelos nossos afluentes, rio, mar, enfim porto aqui pertinho, nossas estradas que graças a deus estão boas, teríamos tudo para que essa evolução acontecesse , é uma cidade linda com um potencial turístico imenso, uma área enorme ainda para ser ocupada, para ser trabalhada e nós aqui esperando acontecer pelo tipo de colonização e resultou em uma acomodação tanto da produção econômica e cultural; pelo tipo de economia, baseada no latifúndio, que não emprega uma mão de obra qualificada, com baixo nível de escolarização. (Entrevistado D)

Entretanto, entre as dificuldades, temos relatos de experiências bem-sucedidas, por exemplo, a entrevistada $\mathrm{F}$ relata que está otimista com a consolidação da marca e com o retorno financeiro, principalmente com a conquista de novos clientes. Já a entrevistada (B), afirma que a empresa conseguiu a certificação do doce pelotense a partir da parceira com o SEBRAE, o que possibilitou a ampliação dos investimentos, principalmente, com os grupos de doceiros. Cabe destacar aqui, que a tradição histórica dos doces, passa a ser certificada por uma instituição de estímulo ao empreendedorismo, conferindo legitimidade simbólica ao produto, conforme o trecho abaixo, 
Adaptamos a empresa para a certificação do doce pelotense, temos toda a linha de bombons, e também os doces de regiões portuguesas, onde nós vamos pegando receitas originais de Portugal e fazendo aqui, adaptando na verdade para nosso clima aqui. A certificação do doce foi o maior empreendimento que o Sebrae e outros investidores puderam fazer com um grupo de doceiros. (Entrevistado B).

As trajetórias também são marcadas por experiências bem-sucedidas que se dão partir dos desafios que tais empreendedores têm frente as dificuldades impostas pela justificativa de falta de apoio do setor público e das dificuldades econômicas que historicamente explicam a região.

Outro ponto abordado na entrevista foi a relação entre a economia nacional e a gaúcha e, como essa dinâmica impacta o empreendimento local. Nessa questão, a fala dos entrevistados se dividem em três grupos, o primeiro considera a economia gaúcha como reflexo da crise econômica no país, gestado, principalmente, pela crise de confiança frente ao quadro político instalado a partir da corrupção. O segundo grupo também invoca a questão da crise, mas como consequência da má gestão pública, ineficiência do gestor, que não incentiva a economia de maneira direta. $\mathrm{O}$ terceiro grupo vê a economia gaúcha "desvinculada" do mercado interno local e nacional, voltada para o agronegócio de exportação.

Na primeira visão (entrevistados E, F e H), as consequências da crise econômica, de acordo com nossos entrevistados, levam o empresário a estar à mercê das dificuldades apresentadas pela crise, não investindo na ampliação do negócio e levando a demissão de funcionários para a redução de custos; afetando os planos de reinvestimentos, que passam a ser pensados apenas quando houver indícios de uma estabilidade econômica, e de retomada do crescimento, como pode ser observado no depoimento da entrevistada:

Agosto de 2015, começou a ficar ruim em todo o Brasil inclusive, simplesmente os pedidos pararam, setembro mesmo não se teve nenhum pedido para outubro. Desse jeito, ficou muito difícil de continuar porque as obrigações não param, era funcionário, impostos, escritório de contabilidade, o que fez com que eu demitisse praticamente todos os funcionários e ficasse apenas com uma. Em março de 2016, começou a melhorar e contratei novamente mais duas pessoas, onde tivemos bastante movimento até setembro, onde começou a ficar ruim novamente, e não está bom, principalmente da maneira de como eu estava trabalhando, direto com as empresas, pois elas também começaram a enfrentar dificuldades. (Entrevistada E) 
O segundo grupo (entrevistados A, D e G), atribui a dificuldade da economia gaúcha a questão da má gestão da administração pública e a guerra fiscal entre os Estados da União:

A economia está enfrentando grandes dificuldades, principalmente o nosso rio grande do sul, está passando por estas dificuldades, a gente sabe por todos os noticiários que a gente ouve, escuta e vê que a realidade não é boa, mas uma coisa que na minha área atrapalha é que eu compro produtos de São Paulo e como nosso imposto é maior eu tenho que pagar uma diferença ainda, então o que que acontece: é que além do custo ser alto, porque compro produto importado e ele vem de São Paulo e chegar aqui no sul e eu tenho que pagar ainda mais imposto isso pra mim fica muito difícil, pois é um custo a mais para o nosso produto. E essa diferença aconteceu num governo de dois anos para cá, nunca pagamos essa diferença, porque não tinha tanta diferença assim, de São Paulo é uns 12/ e a do rio grande do Sul é de 18,5/. E isso causa uma diferença no nosso produto por ter que alterar preço, para nós o custo fica muito mais alto (Entrevistado G).

Novamente, a relação entre economia e empreendimento é dependente da ação externa da administração governamental. É neste ponto, que reclamam da ação do governo estadual, que não interfere ou não tem cacife político, dentro da conjuntura nacional, para modificar a situação fiscal. Quanto a gestão municipal, também relataram a inexistência de uma política fiscal ou de investimento que incentive a atividade comercial varejista.

Assim, dentro desta visão, a crise econômica é reflexo da má gestão e da corrupção, resultado do comportamento dos políticos do país:

A economia hoje está meio estagnada, parada, investimentos, devido a essas coisas erradas na política, tanto aqui no RS, como em Brasília, nós aqui mesmo estamos muito mal, mal representados pela classe política como o resto do Brasil, não temos investimentos, falta infraestrutura, em diversos segmentos da sociedade. (Entrevistado A).

Já o terceiro grupo (entrevistados B, C e I) afirma que a economia gaúcha não desenvolve o mercado interno, pois tem poucas indústrias e está voltada para o agronegócio de exportação, que resulta na pouca circulação de dinheiro, o que dificulta a economia terciária:

Não tenho muito conhecimento assim né, conheço um pouco mais da nossa região, acredito que o comércio aqui de Pelotas apesar de ser razoavelmente desenvolvido, Pelotas pertence a uma região onde tem muito pouco setor secundário e consequentemente não tem muito dinheiro circulando né então o comércio nesse aspecto fica um pouco prejudicado, então a gente conta mais com funcionários públicos e algumas pessoas que tem empresas 
agropecuárias e fora isso o dinheiro aqui é um pouco escasso eu acho. (Entrevistada C).

Neste sentido, sobre as características e constituição da economia gaúcha, as principais respostas se concentraram na agricultura, agronegócio e pecuária de exportação. Uma das entrevistadas (Entrevistada G) afirmou que a economia gaúcha é bem diversificada e somente um dos entrevistados (Entrevistado H) enfatizou a dinâmica recente do Polo Naval, como cenário positivo.

Ao compararem a economia gaúcha com a os demais estados brasileiros, uma vertente (a grande maioria dos entrevistados) afirma que a economia do Rio Grande do sul é fechada, baseada na agricultura e na pecuária (agronegócio) e apesar de ser rica, é mal distribuída, com concentração de renda e, por isso está "parada no tempo", em termos de atração de grandes empresas diferentes do setor agrícola. Já uma segunda visão (os entrevistados C e E) trabalha com o eixo de que a região sul é, em relação ao nordeste do país, mais desenvolvida, já em relação ao sudeste, menos, principalmente no que tange a questão da produção industrial.

O repertório que sustenta a nossa amostra demonstra, novamente, que os entrevistados têm uma percepção de isolamento e estagnação, e relatam a falta de investimento, como pode ser observado no depoimento:

Olha o rio grande do sul tem por característica ser mais fechado, nosso povo é mais fechado, aquela expressão bairrista ela não existe a toa né, eu acho que quando se pensa em rio grande do sul em relação a outros estados, nos olham como um povo mais turrão, mais resistente, e ao longo desses anos as negociações, por exemplo a nível nacional de grandes indústrias, elas chegam aqui no rio grande do sul e encontram resistência, pelos nossos governos sei lá, eu diria até que é uma falta de habilidade nas negociações , até por essas opções indo para outros estados e sim o rio grande do sul precisaria de outros investimentos, que não seja só agricultura e pecuária, primeiro porque permitiria que a nossa mão de obra fosse melhor aproveitada e a nossa produção também agrícola e pecuária, couro, por exemplo, fosse melhor aproveitado, me pergunto porque grandes empresas calçadistas saíram aqui do rio grande do sul, foram lá para cima, o que que aconteceu, porque que não se conversou não se negociou, para que ficassem, a gente sabe que são falta de habilidades na política, na negociação. (Entrevistado D).

Além disso, a orquestração do repertório, de certa forma, vai se tornando homogênea e é fortalecida pela dualidade entre mercado (via uma percepção de que os indivíduos que fazem acontecer o desenvolvimento), e Estado, visto como uma instituição ineficiente no que tange o 
planejamento e a gestão da economia. Assim, na na outra metade "tudo funciona" e o mercado acontece, por aqui o mito do fracasso e do atraso tem como "bode expiatório" a própria ausência de políticas de investimento e de desenvolvimento elaboradas pelo Estado.

\section{Considerações finais}

Ao realizar uma breve revisão sobre a produção acadêmica do desenvolvimento econômico do Rio Grande do Sul, de certa forma, observou-se a relevância e a centralidade da teoria do contraste metade-norte e metade-sul fortemente promovida pelo campo acadêmico, em especial, dos geógrafos e "cegamente" adotada pelos demais segmentos intelectuais como princípio explicativo da atual realidade econômica do Rio Grande do Sul (LEITE; SPOLLE, 2014). Assim, sem desmerecer a relevância da explicação histórica da formação do Rio Grande do Sul, buscamos apresentar, de certa forma via a orquestração (sem maestro) do repertório dos empresários locais, constituído pelo efeito teoria do "princípio explicativo regional" que alimenta subjetivamente as percepções sobre a dinâmica econômica do passado e futuro, e que condena o presente ao cenário de fracasso e atraso, e que (na prática) pode chegar a atravancar o "real" desenvolvimento econômico de uma região e estimular o espírito empreendedor da outra.

O imaginário social do empresário pelotense é constituído por uma relação tempo-espaço, na qual a ideia de pujança econômica está presa ao passado, quando a cidade atingiu o ápice da sua economia via o setor charqueador, e mais recente com o Polo Naval; assim, os mais esperançosos vislumbram um cenário positivo (menos que imbuído de um certo pessimismo - a maldição) para o futuro; já o presente está simbolicamente marcado pelo "princípio explicativo regional”, no qual “aqui nada dá certo", de acordo com o entrevistado I: "A nossa economia, a gaúcha está meio devagar, não sei se é pela crise que a gente está atravessando neste momento, mas eu acho que tem muito a crescer, porque o gaúcho tem muita vontade de trabalhar e tem muitas ideias e isso é o que importa", bem como reforça a entrevistada G "Aqui na confeitaria dificuldades a gente sempre tem, com esses planos a gente sempre enfrenta dificuldades, mas a gente tem que pensar mais para frente, colocar sempre para vender o que chama mais atenção dos clientes, a gente tem os doces tradicionais de Pelotas".(Doceira)

Entre mitos e maldição orquestrado pelo repertório que fortalece a performance do mito do “princípio explicativo regional” compõem o imaginário social da região, sustentando pelos próprios agentes locais, isto é, não é um mito criado, digamos, pelos "de fora"; mas sim, pelos de "dentro" e 
partícipes da lógica social, que cria-se uma verossimilhança com o presente e o efeito teoria concretiza a naturalização do mito.

De modo geral, até o momento, o recorte teórico e empírico da pesquisa nos leva a refletir sobre a existência de dois mundos que alimentam a orquestração do repertório e a naturalização do mito: o primeiro mundo é formado por aqueles que dão força ao campo, isto é, os acadêmicos, em especial, os geógrafos que sustentam a teoria do contraste - legitimando o mito; e, o segundo, composto pelo senso comum, ou melhor, por aqueles que incorporam o mito e são responsáveis pela sua difusão na prática, passando a legitimar a teoria do contraste como "princípio explicativo regional" do atual entrave econômico da região sul, naturalizando práticas e pensamentos capazes de ofuscar a realidade e entravar ou estimular o desenvolvimento.

Deste modo, apontamos que tal prática subjetivamente "se fecha" para o "novo espírito empreendedor"; e, sustenta as (antigas) formas de organizações (políticas e econômicas) de poder concentradas no tradicional comércio varejista e nas "mesmas família"; criando barreiras subjetivas que inibem a formação de alianças com outros setores da economia.

Os caminhos desta pesquisa também irão adentrar, como já enfatizado, pela questão da economia étnica, bem como, analisaremos comparativamente os dados sobre as atividades comerciais, que envolvem abertura e falência de empresas, das metades norte e sul, através da associação comercial gaúcha; já que dados recentes apontam o aumento da extinção e falência de empresas no Rio Grande do Sul, assim, acredita-se também que tal fenômeno é permeado pelo mito, já que de acordo com blog Acerto de Contas, a explicação para este cenário está no baixo desenvolvimento econômico - "Para os economistas da Serasa Experian, é reflexo do baixo dinamismo da atividade econômica, elevação do custo financeiro das empresas (taxas de juros de empréstimos cada vez mais altas), alta do dólar e de outros custos, como energia elétrica e combustíveis" 20 .

\section{Referências}

ALONSO, J. A. F. Análise do crescimento da região sul nas últimas décadas (1959-1990). In: ALONSO, J. A. F.; BENETTI, M. D.; BANDEIRA, P. S. Crescimento econômico da região sul do Rio Grande do Sul: causas e perspectivas. Porto Alegre: FEE, 1994.

20 Dados e informações retiradas do sítio: http://zh.clicrbs.com.br/rs/noticias/noticia/2015/05/aumenta-extincao-efalencia-de-empresas-no-rio-grande-do-sul-4754109.html. Acesso 14 de junho de 2017. 
BOURDIEU, Pierre. O poder simbólico. Rio de Janeiro: Bertrand Brasil, $9^{\circ}$ edição. 2006. . Meditações pascalianas. Rio de Janeiro: Bertrand Brasil, 2001.

CALLON, Michel. The laws of the markets. Oxford: Blackwell, 1998

CARDOSO, Fernando Henrique. Capitalismo e escravidão no Brasil meridional: o negro na sociedade escravocrata do Rio Grande do Sul. Rio de Janeiro: Civilização Brasileira, 2003.

CARGnIN, Antonio Paulo. Políticas de desenvolvimento regional no Rio Grande do Sul: vestígios, marcas e repercussões territoriais. 2011. 317f. Tese (Doutorado em Geografia) Instituto de Geociências, Universidade Federal do Rio Grande do Sul,

Porto Alegre, 2011. Disponível em: http://www.bibliotecadigital.ufrgs.br/da.php?nrb=000817775\&loc=2012\&l=a2753a71 ab57b0a4.

FIALHO, M. A. V. Rincões de pobreza e desenvolvimento: interpretações sobre comportamento coletivo. Tese (Doutorado em Sociologia Rural) Instituto de Ciências Humanas e Sociais, Universidade Federal do Rio de Janeiro, Rio de Janeiro, 2005.

HEIDRICH, A.L. Além do latifúndio: geografia do interesse econômico gaúcho. Porto Alegre: Ed. Universidade/UFRGS, 2000.

LEITE, E. S.; SPOLLE, M. V. Desvelando as contradições da teoria do desenvolvimento do Rio Grande do Sul. In: V Seminário Nacional de Sociologia e Política: desenvolvimento e mudanças sociais em contexto de crise, 2014, Curitiba - PR. Anais: V Seminário Nacional de Sociologia e Política, 2014.

REICHEL, H. J. A industrialização no Rio Grande do Sul na República Velha. In: GONZAGA, S.; DACANAL, J. H. RS: economia e política. Porto Alegre: Mercado Aberto, 1979.

SAINT-HILAIRE, August. Viagem ao Rio Grande do Sul. Brasília: Senado Federal, Conselho Editorial, 2002.

SCHNEIDER, Sergio; FIALHO, Marco Antônio Verardi. Pobreza rural, desequilíbrios Regionais e desenvolvimento agrário no Rio Grande do Sul. Teoria e Evidência Econômica, Passo Fundo - RS, v. 8, n. 15, p. 117-149, 2000. 